\title{
Study on Complex Formation of Fluorescein-p-Sulfonatocalix[4]arene by Spectroscopic Methods
}

\author{
Sharadchandra Gawhale1, Yogita Thakare², Dipalee Malkhede ${ }^{3 *}$, Gajanan Chaudhari2* \\ ${ }^{1}$ Department of Applied Chemistry, AISSMS-COE, Pune, India \\ ${ }^{2}$ Department of Chemistry, Shri.Shivaji Science College, Amravati, India \\ ${ }^{3}$ Department of Chemistry, University of Pune, Pune, India \\ Email: "gnchaudhari@gmail.com, ${ }^{*}$ ddm@chem.unipune.ac.in
}

Received 10 July 2014; revised 5 August 2014; accepted 29 August 2014

Copyright (C) 2014 by authors and Scientific Research Publishing Inc.

This work is licensed under the Creative Commons Attribution International License (CC BY).

http://creativecommons.org/licenses/by/4.0/

(c) (i) Open Access

\begin{abstract}
The aqueous solution of p-Sulfonatocalix[4]arene-fluorescein complex has been studied based on fluorescence and 1H NMR spectroscopic results. It has been found that the fluorescence intensity quenches regularly upon addition of p-SCX4. The proposed interaction mechanism between pSCX4 and FL indicates that FL partially goes into the cavity of p-SCX4 with the help of strong electrostatic and $\pi-\pi^{*}$ interaction. The quenching constants and stability constants are determined by p-SCX4-FL systems. The proposed inclusion complex is discussed on 1H NMR results. Results are consistent with experimental data obtained from NMR spectroscopy.
\end{abstract}

\section{Keywords}

p-Sulfonatocalix[4]arene, Fluorescein, Electrostatic Interactions, Hydrophobic Interaction, 1H NMR Analysis

\section{Introduction}

p-Sulfonatocalix[n]arene is a family of water soluble calixarene derivatives which have gained considerable attention in the fields of molecular recognition and sensing. Aqueous systems are particularly interesting for complexation studies because one can expect hydrophobic forces to play an important role [1]. Calixarenes are known to form inclusion complexes with a variety of guest molecules in solution and in a solid state, since their inherent annular structure exists stable in both phases [2].

${ }^{*}$ Corresponding authors.

How to cite this paper: Gawhale, S., Thakare, Y., Malkhede, D. and Chaudhari, G. (2014) Study on Complex Formation of Fluorescein-p-Sulfonatocalix[4]arene by Spectroscopic Methods. Optics and Photonics Journal, 4, 237-245.

http://dx.doi.org/10.4236/opj.2014.49024 
Inclusion complexes are chemical species consisting of two or more associated molecules in which one of the molecules forms a cavity into which it can admit a guest molecule resulting in a stable association without formation of any covalent bonds such as electrostatic interaction, cation- $\pi$ interactions, hydrogen bonding, van der Waals and hydrophobic interactions [3]. p-Sulfonic calix[n]arenes provided not only hydrophobic environment (benzene rings) with the above favorable properties, but also hydrophilic heads (sulfonates) and form water soluble encapsulated complexes [4]. Many researchers have studied inclusion properties of water soluble calixarenes with organic ions and neutral molecules [5]-[15]. Secondary forces are alone responsible for maintenance of the integrity of all inclusion complexes. The molecular ratio of guest to calixarene is usually found to be 1:1. However this can change depending on the shape and geometry of the guest and calixarene. The minimum requirement for an inclusion complex formation is size compatibility between host and guest molecules, i.e. guest molecules must fit, entirely or at least partially, into the calixarene cavity [16] [17].

We use FL as a guest molecule because fluorescein derivatives are the most common fluorescent reagents for biological research because of their high absorptivity and excellent fluorescence quantum yield. The present study investigate the formation for complexation of fluorecscein by water soluble p-Sulfonatocalix[4]arene and discuss about their interaction.

\section{Experimental Section}

The p-SCX4 is purchased from TCI chemicals with $99.0 \%$ purity and used as it is. Fluorescein (FL) was procured from Sigma-Aldrich. All aqueous solutions were prepared with ultrapure water obtained from a Millipore Milli-Q. For all experiments $\mathrm{pH}$ was adjusted to 3.5 using dilute $\mathrm{HCl}$.

$\mathrm{pH}$ was measured by digital pH meter of Elico LI 120 make with combined glass and calomel electrode. Absorbance spectra were performed on Shimadzu UV-1800 spectrophotometer. The variation in fluorescence intensity for the determination of stability constants were monitored on a Jasco FP-8300 spectrofluorometer using $1 \mathrm{~cm} \times 1 \mathrm{~cm}$ quartz cell. The excitation wavelength was set at $511 \mathrm{~nm}$. Emission spectra were collected in the range $290-600 \mathrm{~nm}$. The slits for the excitation and emission monochromator were fixed at $2.5 \mathrm{~nm}$. The NMR experiments were performed on a Varian mercury YH-300 spectrometer.

An appropriate volume of $1 \times 10^{-6} \mathrm{M} \mathrm{FL}$ was taken in cuvette. To this solution $1 \times 10^{-4} \mathrm{M}$ solution of pSCX4 was added in different volumes. NMR data was collected by adding $1-2 \mathrm{M}$ concentrations of p-SCX4 to $2 \mathrm{M} \mathrm{FL}$ in $\mathrm{D}_{2} \mathrm{O}$.

\section{Results and Discussion}

The sulfonic acid moieties of p-SCXn hosts are completely dissociated at $\mathrm{pH} 0.4$ and the pKa value of the first dissociation step of the phenolic $\mathrm{OH}$ groups is in the range of $3.00-3.7$ showing slight growth with the ring size. Therefore, all readings were taken at $\mathrm{pH} 3.5$ [18]. A large part of our existing knowledge of noncovalent binding is based on the measurement of equilibrium constants. Equilibrium constants afford the scientist information of the mechanism of the chemical process involved.

Despite multiple reports [19] otherwise, we assume only one ligand may occupy each receptor (or host) site. A scheme for this event may be represented by,

$$
\mathrm{nG}+\mathrm{H} \leftrightarrow \mathrm{HGn}
$$

where $\mathrm{n}$ signifies the maximum number of binding sites on substrate $\mathrm{H}$ and $\mathrm{G}$ denotes the ligands that are free to bind to each site.

$$
\text { At equilibrium, } \mathrm{Ks}=[\mathrm{HG}] /[\mathrm{H}][\mathrm{G}]
$$

where $[\mathrm{H}],[\mathrm{G}]$ and $[\mathrm{HG}]$ represent the concentration of the host, guest and supramolecular inclusion complex respectively.

\subsection{UV-Visible Absorption Spectral Titration}

By keeping the concentration of the FL fixed at $1 \times 10^{-6} \mathrm{M}$ and varying the concentration of the host-pSCX4, UV-visible absorption spectrum of FL was recorded. The fall in absorbance is observed showing blue shift with change in maximum absorbance wavelength from $479 \mathrm{~nm}$ to $472 \mathrm{~nm}$. Also it is observed that with each addition the first shoulder increasing with decreasing second shoulder indicates transition from $n$ to $\pi^{*}$ (Figure 1). The 
stability constant (Ks) which controls the equilibrium between the free ligand and the complex was obtained from the variation of either absorbance or fluorescence intensity at proper observation wavelengths [20]. The stability constant was calculated as $1.95 \times 10^{4} \mathrm{M}^{-1}$ which also indicates strong binding between p-SCX4 and FL (Figure 2).

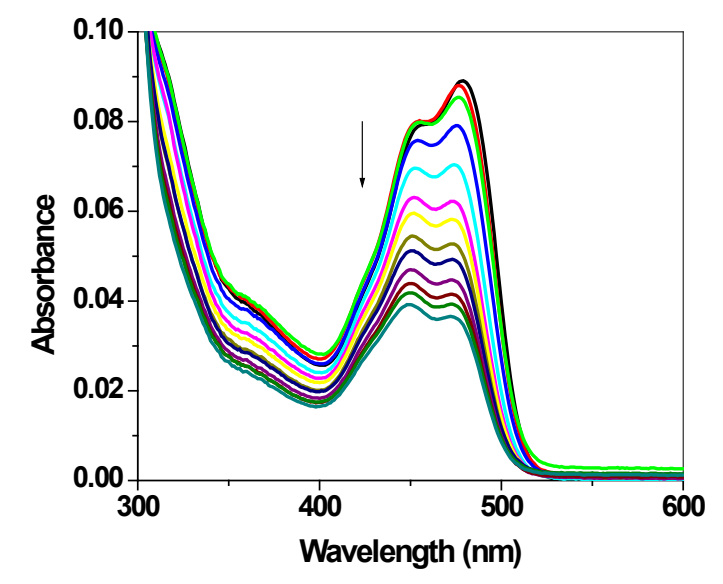

Figure 1. Absorption spectra of guest, FL $\left(1 \times 10^{-6}\right.$ $\mathrm{M})$ with the addition of different concentrations of host, p-SCX4 $\left(10-1000 \mu \mathrm{l}, 1 \times 10^{-4} \mathrm{M}\right)$.

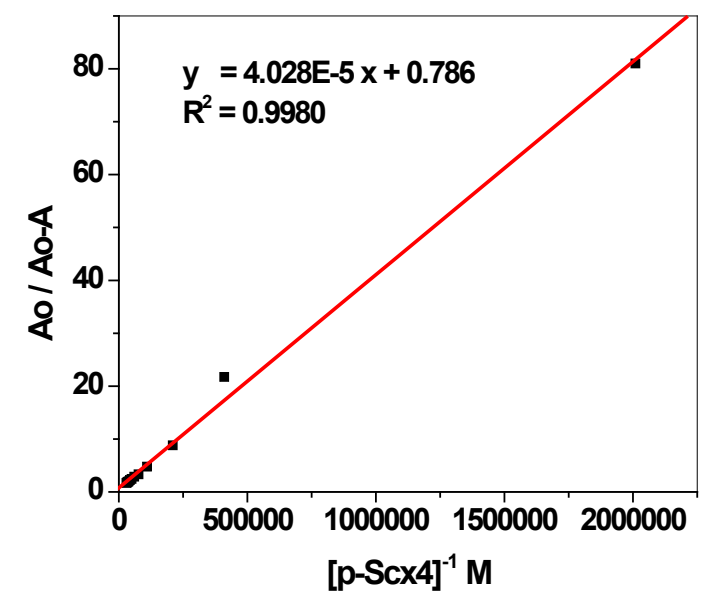

Figure 2. Binding constant $=1.95 \times 10^{4} \mathrm{M}^{-1}$.

\subsection{Fluorescence Spectral Titrations}

To assess the inclusion complexation behavior of p-SCX4-FL system, spectral titrations were performed at $25^{\circ} \mathrm{C}$ in aqueous solution by measuring fluorescence measurement. Figure 3 shows fluorescence spectroscopy experiments which were carried out at scan speed $500 \mathrm{~nm} / \mathrm{min}$, sensitivity medium, and response time of 1 second. Initially spectral changes were recorded of FL having concentration $1 \times 10^{-6} \mathrm{M}$ with gradual addition of p-SCX4 having concentration $1 \times 10^{-4} \mathrm{M}$. The stepwise increase of concentration of the host causes significant reduction in fluorescence intensity with no change in peak shape of dye. When FL was excited at $460 \mathrm{~nm}$, the maximum emission wavelength was observed at $511 \mathrm{~nm}$. With the addition of p-SCX4, the maximum emission wavelength was a bit blue-shifted from $508-511 \mathrm{~nm}$, indicating the formation of host-guest inclusion complex between p-SCX4-FL (Figure 3). The fluorescence intensity of the first band (510 nm; excitation wavelength $460 \mathrm{~nm}$ ) decreased markedly with increasing calixarene concentration, owing to the quenching effect of the calixarene ח-system. The possible explanation for decrease in the fluorescence intensity of dye with the addition of p-SCX4 is that the increase in polarity or hydrophilicity around the dye molecules causes much higher fluorescent quenching [21]. 


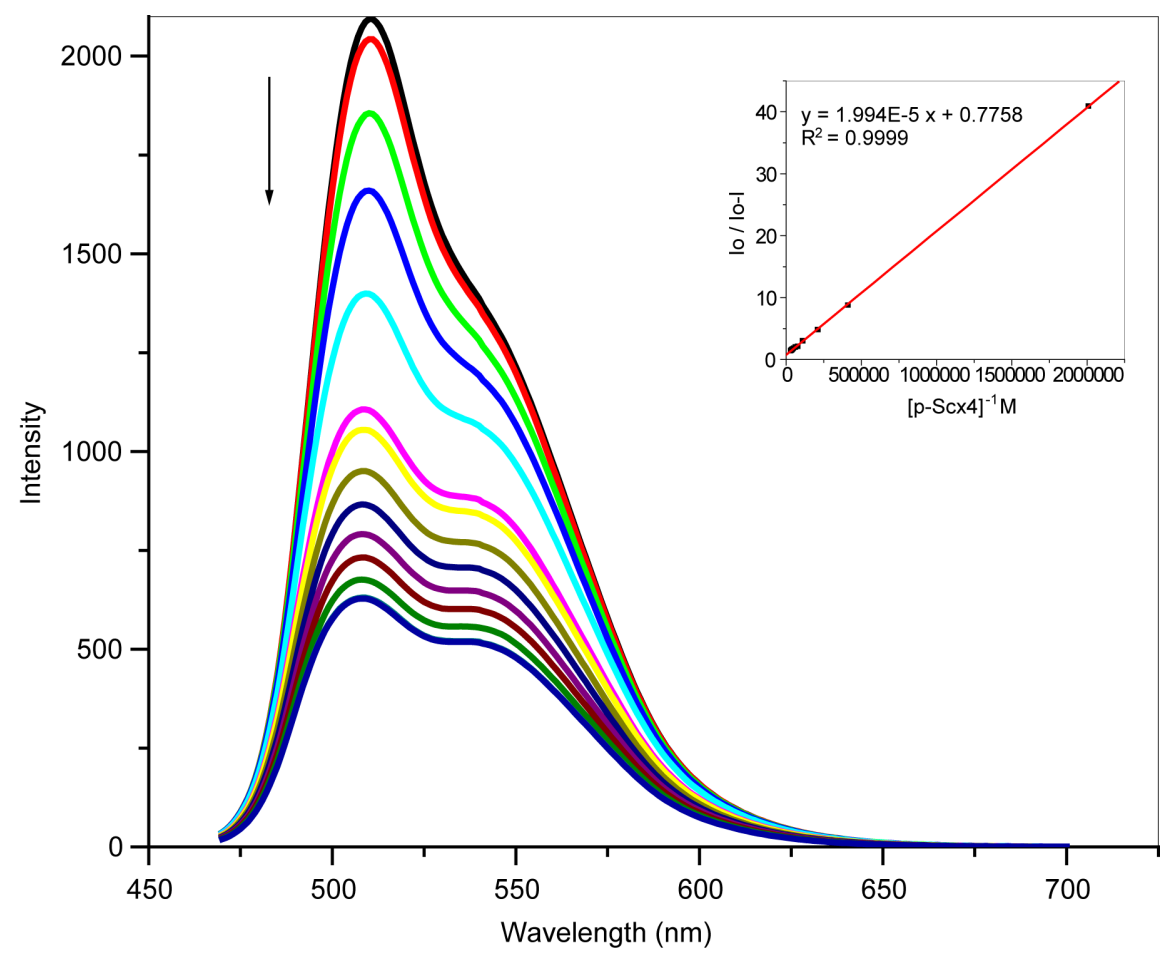

Figure 3. Fluorescence emission spectra $(\lambda$ ex $511 \mathrm{~nm})$ of FL $\left(1 \times 10^{-6} \mathrm{M}\right)$ at different concentration of p-SCX4 $\left(10-300 \mu \mathrm{l}, 1 \times 10^{-4} \mathrm{M}\right)$, at $\mathrm{pH}=3.5$. The inset shows i) SternVolmer plot of fluorescence quenching of FL Vs $[\mathrm{p}-\mathrm{SCX} 4]^{-1}, \mathrm{Ksv}=1.36 \times 10^{-5} \mathrm{M}$.

Stern-Volmer analysis was utilized to probe the nature of the quenching process in the complex formation. Stern-Volmer plot is a useful method of presenting data on emission quenching. Plotting relative emission intensities Io/I against quencher concentration yields alinear Stern-Volmer plot for a static quenching process (Figure 4). Slope of the line gives Ksv, static quenching constant. I and Io are the initial and final fluorescence intensities.

$$
\mathrm{I} / \mathrm{I}=\mathrm{Ksv}[\mathrm{G}]+1
$$

The complex stability constant was calculated using Valeur's method [22]. The quantity Io/Io-I is plotted against [p-SCX4] with the stability constant given by the ratio of intercept/slop [23]. Stability constants for complexation of p-SCX4-FL are approximately the same calculated by two methods, spectrophotometric and spectrofluorometric.

\subsection{Inclusion Mechanism}

To explore the possible inclusion model between p-SXC4 and FL (Figure 5), 1H NMR titration experiments were carried out at $25^{\circ} \mathrm{C}$ in $\mathrm{D}_{2} \mathrm{O}$. The $1 \mathrm{H}$ NMR spectra of $1: 1$ equivalent of $\mathrm{FL}$ and $\mathrm{p}$-SCX4 is taken. The $1 \mathrm{H}$ NMR spectra of $1 \times 10^{-3}$ M FL with different concentration of p-SCX4 is shown in Figure 6. For the FLp-SCX4 system the change in chemical shifts of aromatic protons and $\mathrm{ArCH}_{2} \mathrm{Ar}$ methylene protons clearly indicate the incorporation of FL in the cavity of p-SCX4. The chemical shift values of aromatic ring protons of p-SCX4 decreases from 7.38 to $7.36 \mathrm{ppm}$, due to the formation of the complex between p-SCX4 and FL. As can be seen from Table 1(a) and Table 1(b), the chemical shift values of the protons in Fluorescein (H2, H4, H5, H9, H10, H11, H12) changed upon complexation. Also it is observed that peaks of carbon atoms 4 and 5 are merge because of same chemical environment. These observations suggest that the stronger interaction exists between the FL and p-SCX4, which indicates that the p-SCX4 cavity includes upper rim of FL (Figure 7). It is well known that the complexation between the guest and Calixarene are formed by weak forces including hydrogen bonding, $\pi-\pi$ interaction, dipole-dipole or van der Waals. Generally, in the process of the formation of the inclusion complex, the key force depends on the structure, the charge, functional group of guest and host [24]. 


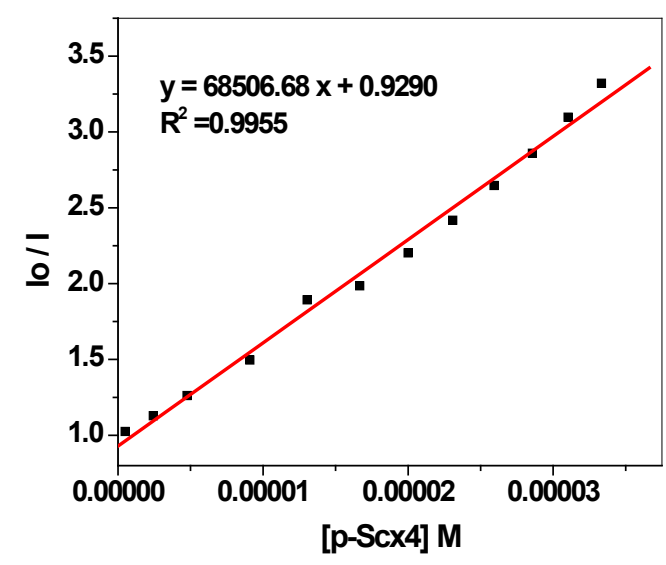

Figure 4. The plot of nonlinear least-squares fitting used for the association constant. $\mathrm{I}_{0} / \mathrm{I}_{0}-\mathrm{I}$ vs. $[\mathrm{p}-\mathrm{SCX} 4]^{-1}$, Binding constant $=3.89 \times 10^{4} \mathrm{M}^{-1}$.<smiles>O=C(O)c1ccccc1-c1c2ccc(=O)cc-2oc2cc(O)ccc12</smiles>

11

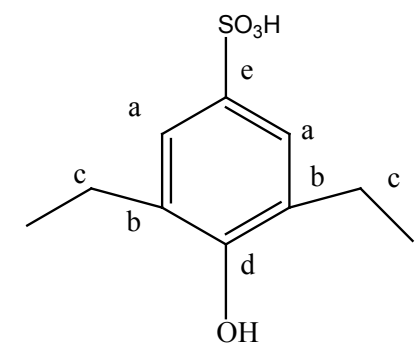

Figure 5. Protons shown in Fluoroescein and p-SCX4.

Table 1. (a) 1H chemical shift values of SCX4; (b) 1H chemical shift values of Fluorescein.

(a)

\begin{tabular}{|c|c|c|c|c|c|c|c|}
\hline & & $\mathrm{a}$ & & $\mathrm{b}$ & $\mathrm{c}$ & d & e \\
\hline $\mathrm{SCX} 4$ & & 7.38 & & quartet & 3.94 & quartet & quartet \\
\hline SCX4-Fluorescein 1 & & 6.97 & & quartet & 3.53 & quartet & quartet \\
\hline 2 & & 6.97 & & quartet & - & quartet & quartet \\
\hline 3 & & 6.98 & & quartet & - & quartet & quartet \\
\hline 4 & & 6.99 & & quartet & - & quartet & quartet \\
\hline 5 & & 7.36 & & quartet & - & quartet & quartet \\
\hline \multicolumn{8}{|c|}{ (b) } \\
\hline & 2 & & 4,5 & 9 & 10 & 11 & 12 \\
\hline Fluorescein & 6.73 & & 6.59 & 7.31 & 7.78 & 7.81 & 8.03 \\
\hline SCX4-Fluorescein 1 & 6.29 & & 6.15 & 6.86 & 7.33 & - & 7.57 \\
\hline 2 & 6.29 & & 6.15 & 6.85 & 7.33 & 7.36 & 7.58 \\
\hline 3 & 6.29 & & 6.15 & 6.84 & 7.32 & 7.36 & 7.58 \\
\hline 4 & 6.30 & & 6.15 & 6.84 & 7.32 & 7.36 & 7.58 \\
\hline 5 & 6.66 & & 6.51 & 7.20 & 7.68 & 7.72 & 7.94 \\
\hline
\end{tabular}


S. Gawhale et al.

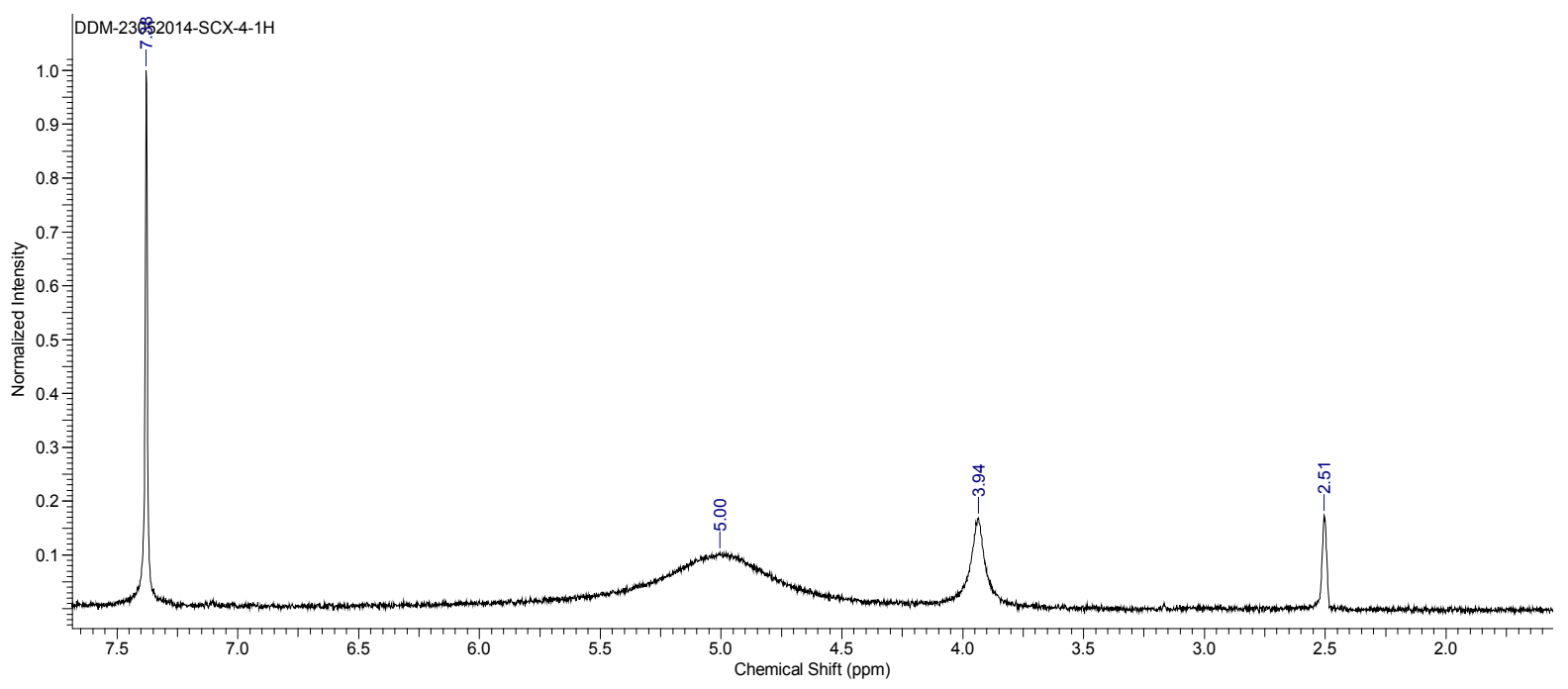

(a)

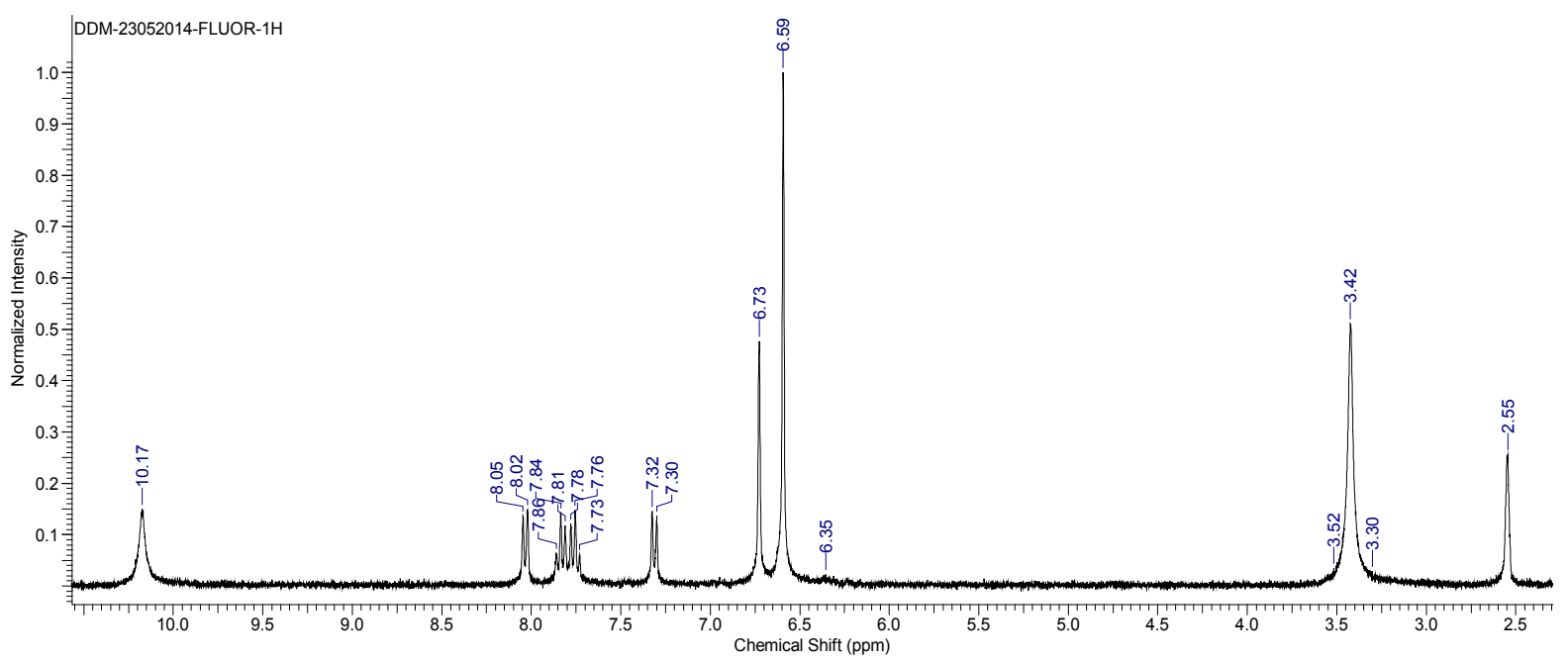

(b)

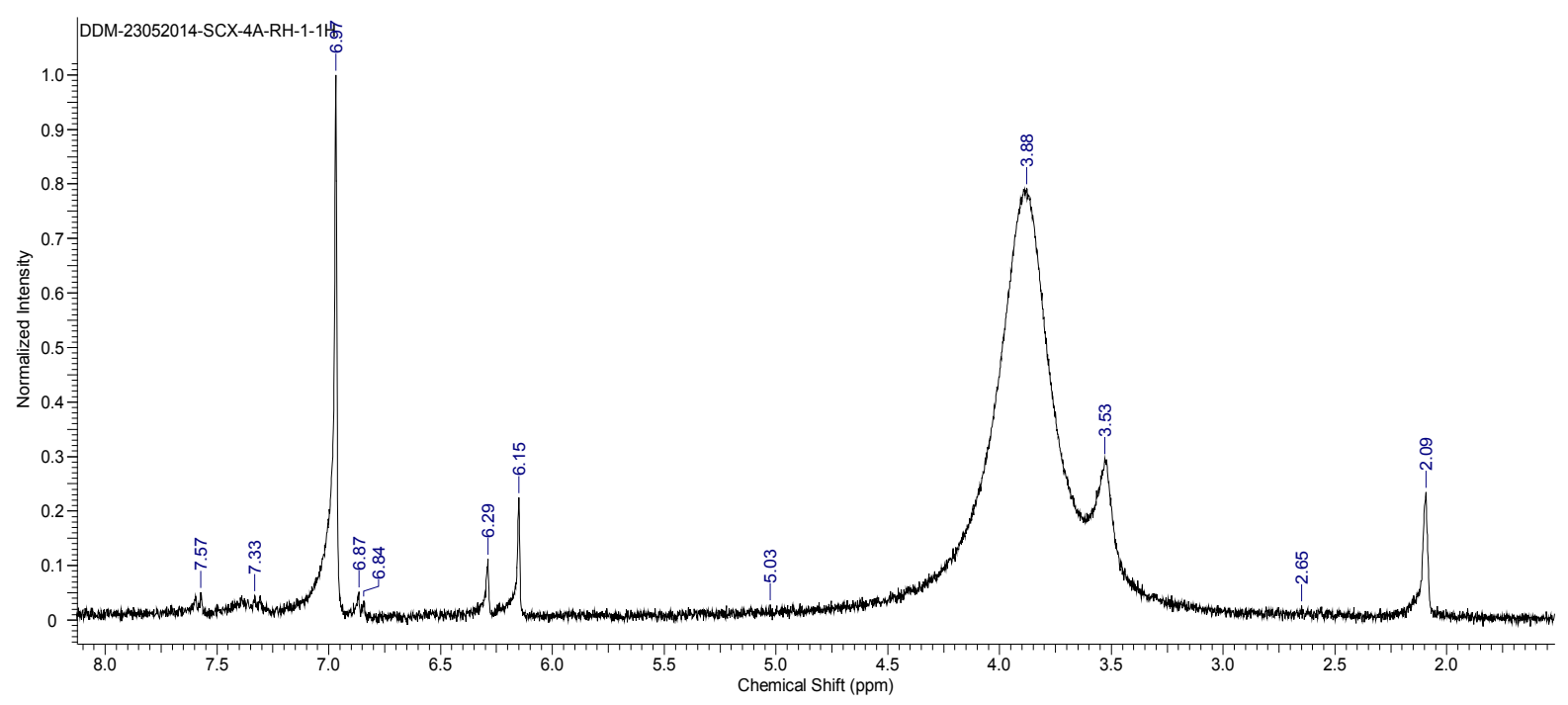

(c) 


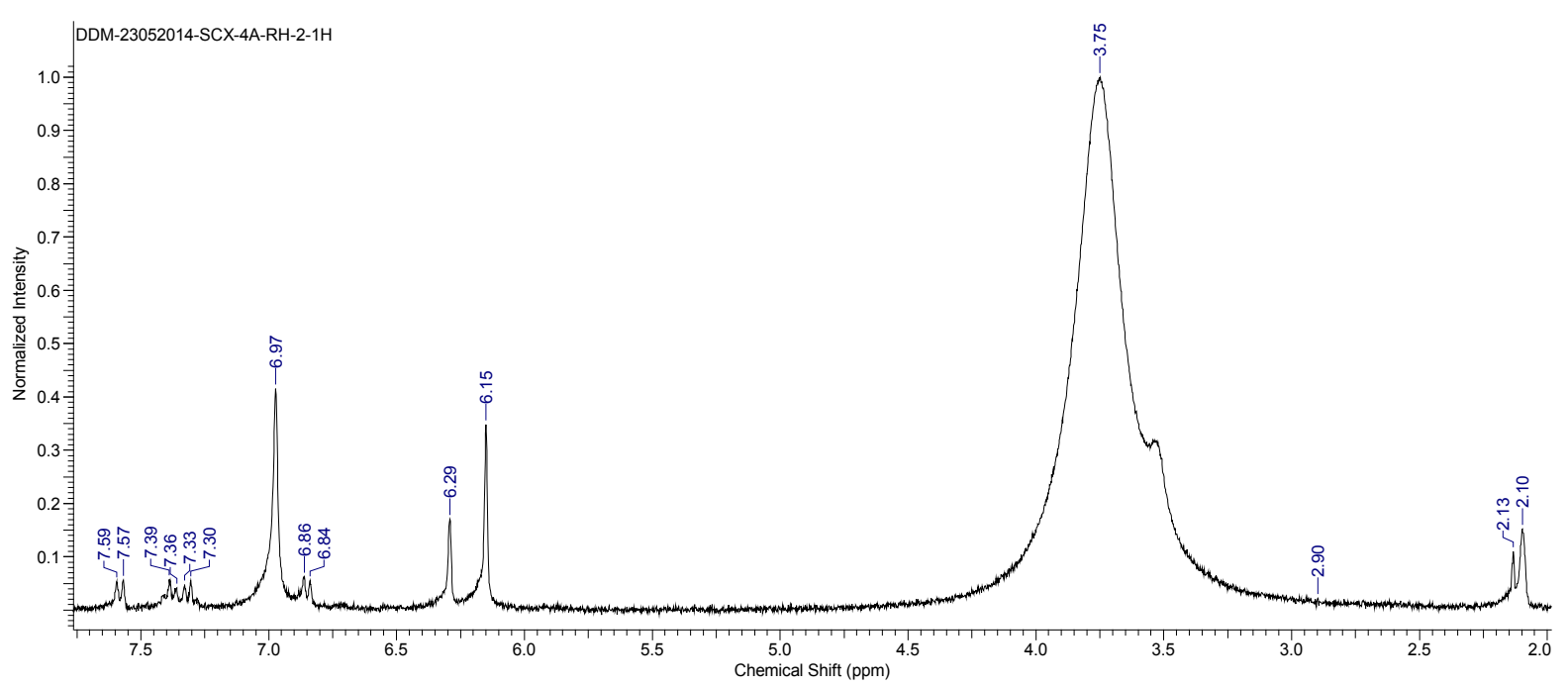

(d)

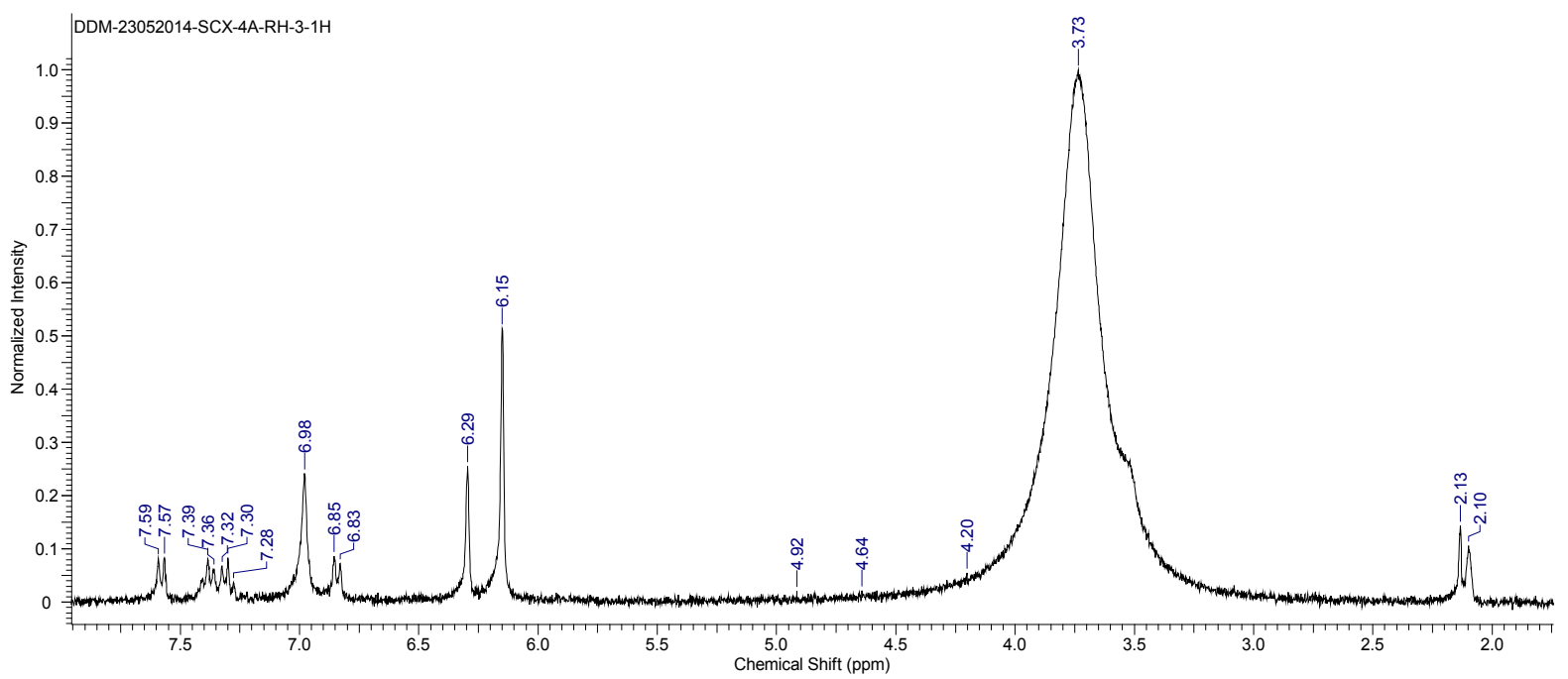

(e)

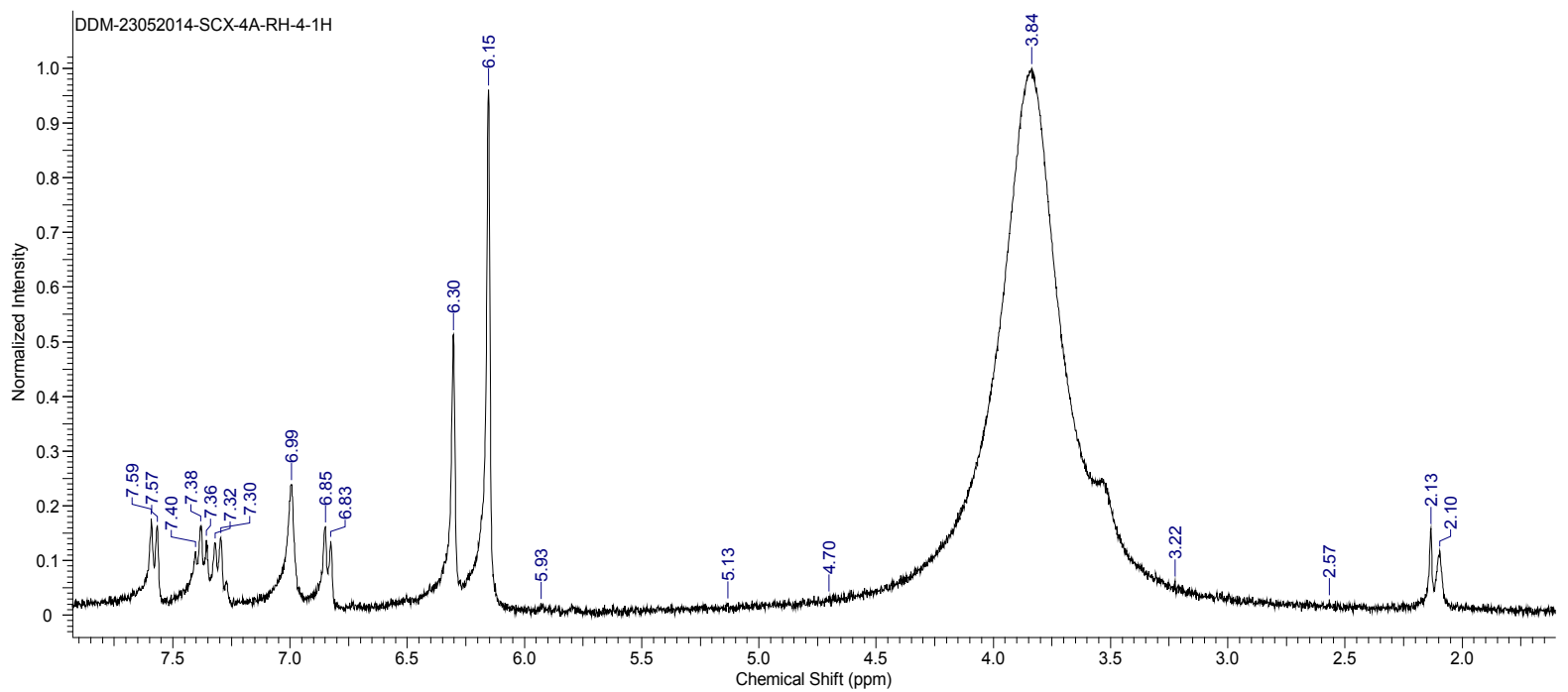

(f) 


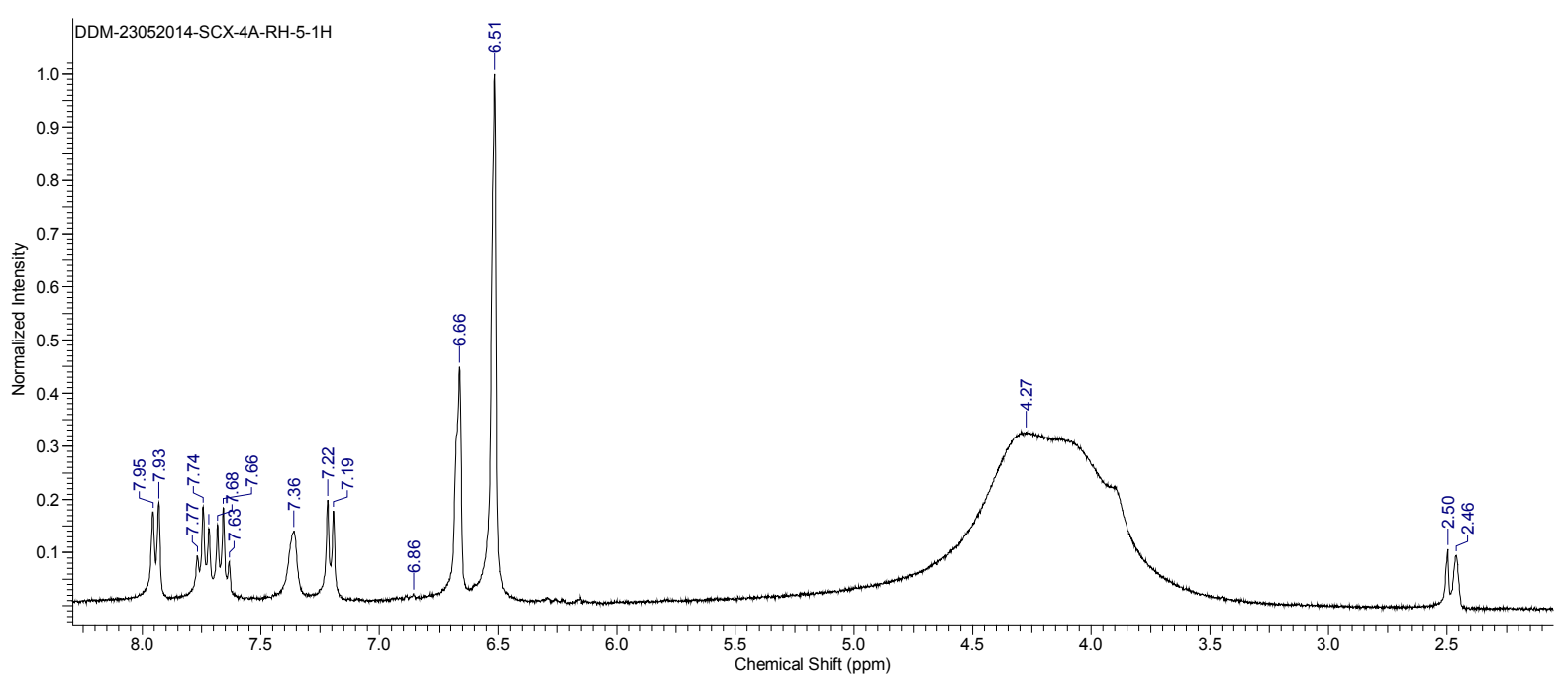

(g)

Figure 6. (a-g): 1H NMR spectra of (a) FL, (b) p-SCX4 and (c-g) mixture of FL+ p-SCX4. (a) SCX4, (b) Fluorescein, (c) p-SCX4-Fluorescein-1, (d) p-SCX4-Fluorescein-2, (e) p-SCX4-Fluorescein-3, (f) p-SCX4-Fluorescein-4, (g) p-SCX4Fluorescein-5.

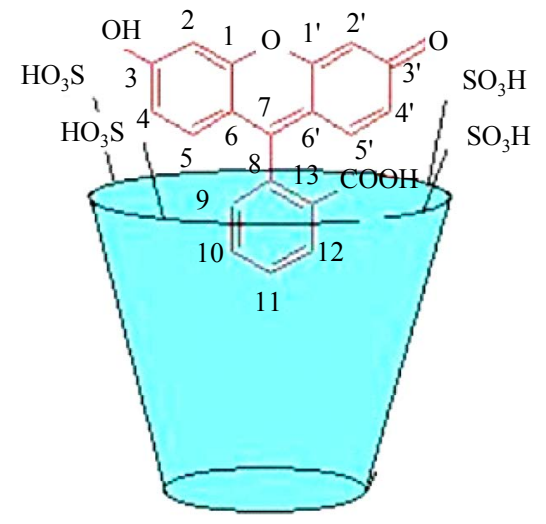

Figure 7. The proposed inclusion pattern of FL-p-SCX4 complex.

\section{Conclusion}

The formation constant of the p-Sulfonatocalix[4] arene with FL system has been performed by spectrophotometric and spectrofluometric titrations in water. It has been shown from NMR data that FL is inserted partially into the cavity of p-SCX4 due to favorable formation constant of $\pi-\pi$ interactions with benzene rings and electrostatic interactions with the $\mathrm{SO}_{3}^{-}$groups. To know more about noncovalent interaction a more elaborated study of 2D ROESY NMR is required which is in pipeline. The molecule which can accommodate molecular guest through complementary noncovalent interactions is attracting researchers particularly for applications in biology. This work may extend the application range of water soluble calixarenes in biochemistry and pharmaceutical analysis.

\section{Acknowledgements}

STG and DDM acknowledge financial support from University Grants Commission, New Delhi, India.

\section{References}

[1] Shinkai, S., Araki, K., Mastsuda, T., Nishijama, N., Ikeda, H., Takasuand, I. and Iwamoto, M. (1990) NMR and Crys- 
tallographic Studies of a p-Sulfonatocalix[4]arene-Guest Complex. Journal of the American Chemical Society, 112, 9053-9058. http://dx.doi.org/10.1021/ja00181a004

[2] Lakowicz, J.R. (2006) Principles of Fluorescence Spectroscopy. 3rd Edition, Springer, Berlin. http://dx.doi.org/10.1007/978-0-387-46312-4

[3] Shinkai, S. (1993) Calixarenes-The Third Generation of Supramolecules. Tetrahydron, 49, 8933-8968.

[4] Alexis, M., Alberto, S., Gerhard, A. and Enrique, M. (2011) Host-Guest Interactions between Calixarenes and $\mathrm{Cp}_{2} \mathrm{NbCl}_{2}$. Journal of Organometallic Chemistry, 696, 2419-2527. http://dx.doi.org/10.1016/j.jorganchem.2011.03.021

[5] Kunsági-Mátéa, S., Szabó, K., Lemlia, B., Bitter, I., Nagy, G. and Kollár, L. (2005) Host-Guest Interaction between Water-Soluble Calix[6] arene Hexasulfonate and p-Nitrophenol. Thermochimica Acta, 425, 121-126. http://dx.doi.org/10.1016/j.tca.2004.06.015

[6] Zhou, Y.Y., Ding, X.P., Fang, X.L., Li, T., Tang, D.B. and Lu, Q. (2011) Studies on the Inclusion Behavior of Amphiphilic $p$-Sulfonatocalix[4]arene with Ascorbic Acid by Spectrofluorometric Titrations. Optics and Photonic Journal, 1, 59-64. http://dx.doi.org/10.4236/opj.2011.12009

[7] Zhou, Y.Y., Lu, Q., Liu, C., She, S. and Wang, L. (2006) Study on the Inclusion Behavior of p-Sulphonatocalix[4]arene with 9-Amino-Acridine by Spectrofluorometric Titrations. Spectrochimica Acta Part A: Molecular and Biomolecular Spectroscopy, 63, 423-426. http://dx.doi.org/10.1016/j.saa.2005.04.056

[8] da Sliva, D.L., do Couto Tavares, E., de Souza Conegero, L., de Fatima, A., Pilli, R.A. and Fernandes, S.A. (2011) NMR Studies of Inclusion Complexation of the Pyrrolizidine Alkaloid Retronecine and $p$-Sulfonic Acid Calix[6]arene. Journal of Inclusion Phenomena and Macrocyclic Chemistry, 69, 149-155. http://dx.doi.org/10.1007/s10847-010-9825-1

[9] Wang, K., Guo, D.S., Zhang, H.Q., Li, D., Zheng, X.L. and Liu, Y. (2009) Highly Effective Binding of Viologens by p-Sulfonatocalixarenes for the Treatment of Viologen Poisoning. Journal of Medicinal Chemistry, 52, 6402- 6412.

[10] Mareeswaran, P.M., Babu, E., Sathish, V., Kim, B., Woo, S.I. and Rajagopa, S. (2014) P-Sulfonatocalix[4]arene as a Carrier for Curcumin. New Journal of Chemistry, 38, 1336-1345. http://dx.doi.org/10.1039/c3nj00935a

[11] Miskolczy, Z. and Biczok L. (2009) Inclusion Complex Formation of Ionic Liquids with 4-Sulfonatocalixarenes Studied by Competitive Binding of Berberine Alkaloid Fluorescent Probe. Chemical Physics Letters, 477, 80-84.

[12] Liu, Y., Han, B.-H. and Chen, Y.-T. (2002) Molecular Recognition and Complexation Thermodynamics of Dye Guest Molecules by Modified Cyclodextrins and Calixarenesulfonates. The Journal of Physical Chemistry B, 106, 46784687. http://dx.doi.org/10.1021/jp015603r

[13] Liu, Y., Han, B.-H. and Chen, Y.-T. (2000) Inclusion Complexation of Acridine Red Dye by Calixarenesulfonates and Cyclodextrins: Opposite Fluorescent Behavior. The Journal of Organic Chemistry, 65, 6227-6230. http://dx.doi.org/10.1021/j0991654x

[14] Fei, X.N., Zhang, Y., Zhu, S., Liu, L.J. and Yu, L. (2013) Spectral Study and Protein Labeling of Inclusion Complex between Dye and Calixarene Sulfonate. Applied Spectroscopy, 67, 520-525.

[15] Arena, G., Contino, A., Gulino, F.G., Magri, A., Sciotto, D. and Ungaro, R. (2000) Complexation of Small Neutral Organic Molecules by Water Soluble Calix[4]arenes. Tetrahedron Letters, 41, 9327-9330. http://dx.doi.org/10.1016/S0040-4039(00)01687-7

[16] Steed, J.W. and Atwood, J.L. (2009) Supramolecular Chemistry. Wiley Publication, Hoboken.

[17] Sliwa, W. and Kozlowski, C. (2009) Calixarenes and Resorcinarenes. Wiley Publication, Hoboken.

[18] Gutsche, D.C. (2008) Calixarene: An Introduction. Royal Society of Chemistry, London.

[19] Brayant, W.S., Guzei, I.A., Rheigold, A.L., Merola, J.S. and Gibson, H.W. (1998) A Study of the Complexation of $\operatorname{Bis}(m$-Phenylene) Crown Ethers and Secondary Ammonium Ions. The Journal of Organic Chemistry, 63, 7634-7639.

[20] Sahin, O. and Yilmaz, M. (2011) Synthesis and Fluorescence Sensing Properties of Novel Pyrene-Armed Calix[4]arene Derivatives. Tetrahedron, 67, 3501-3508. http://dx.doi.org/10.1016/j.tet.2011.03.035

[21] Zhang, Y.L., Pham, T.H., Pena, M.S., Agbaria, R.A. and Warner, I.M. (1998) Spectroscopic Studies of Brilliant Cresyl Blue/Water-Soluble Sulfonated Calix[4]arene Complex. Applied Spectroscopy, 52, 952-957. http://dx.doi.org/10.1366/0003702981944760

[22] Bourson, J. and Valeur, B. (1989) Ion-Responsive Fluorescent Compounds. 2. Cation-Steered Intramolecular Charge Transfer in a Crowned Merocyanine. The Journal of Physical Chemistry, 93, 3871-3876. http://dx.doi.org/10.1021/j100346a099

[23] Valeur, B. (2001) Molecular Fluorescence Principles and Applications. Wiley-VCH, Weinheim. http://dx.doi.org/10.1002/3527600248

[24] Asfari, M.-Z., Böhmer, V., Harrowfield, J. and Jacques, V. (2001) Calixarene 2001. Springer, Berlin. 
Scientific Research Publishing (SCIRP) is one of the largest Open Access journal publishers. It is currently publishing more than 200 open access, online, peer-reviewed journals covering a wide range of academic disciplines. SCIRP serves the worldwide academic communities and contributes to the progress and application of science with its publication.

Other selected journals from SCIRP are listed as below. Submit your manuscript to us via either submit@scirp.org or Online Submission Portal.
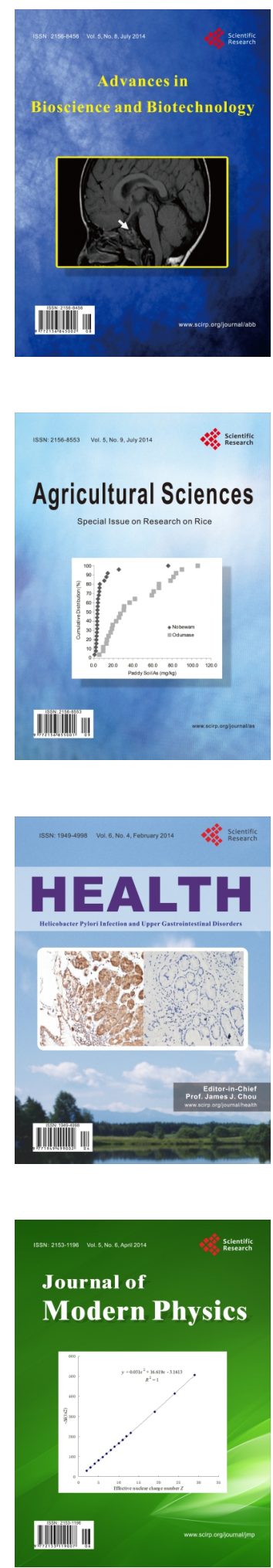
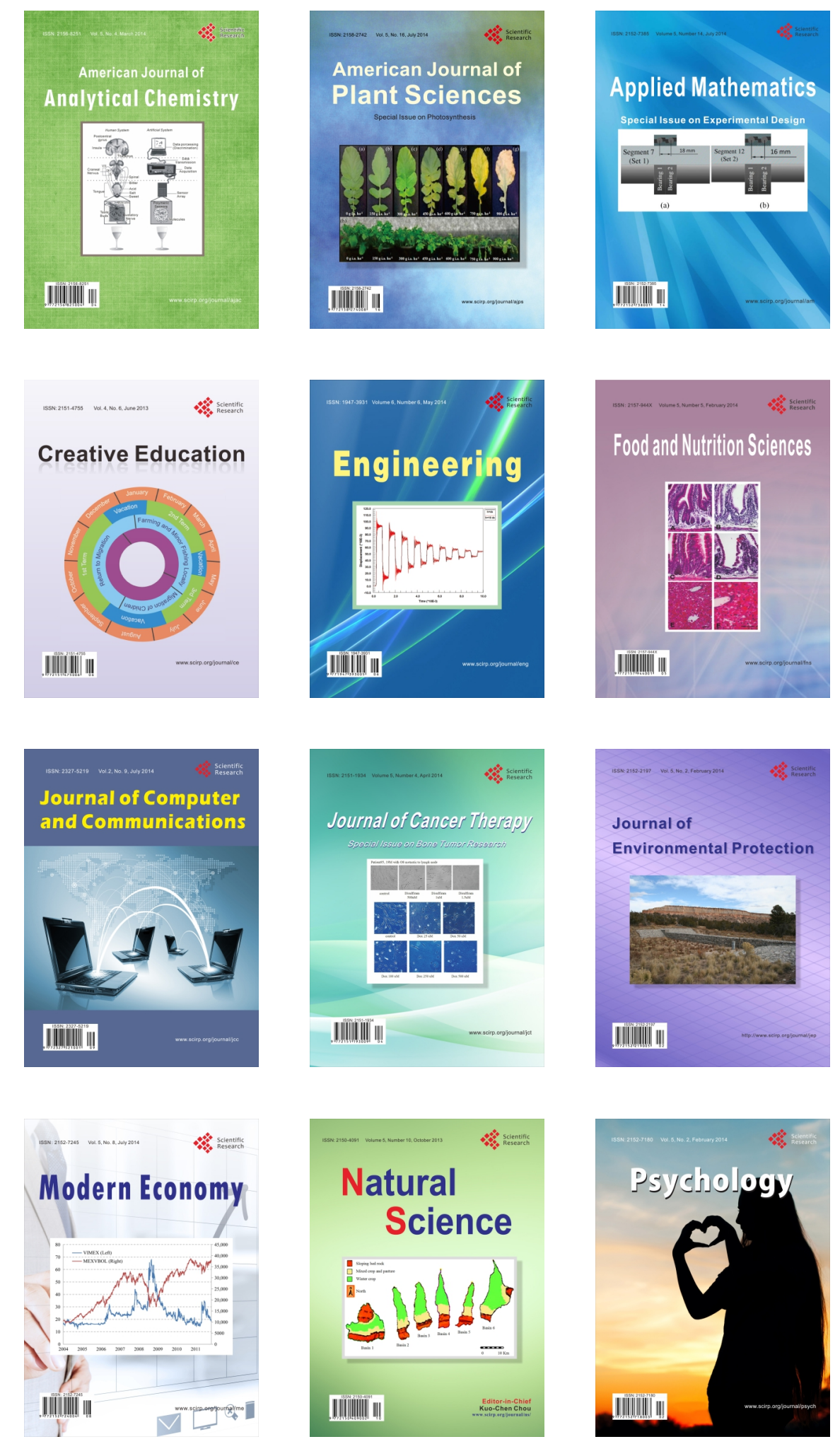